\title{
Incremental versus maximum bite advancement during Twin-block therapy: A randomized controlled clinical trial
}

\author{
Phil Banks, BDS, LDS, FDS, MSc, DOrthRCSEng, ${ }^{a}$ Jean Wright, MSc, BSc, ${ }^{b}$ and \\ Kevin O'Brien, PhD, MSc, BDS, FDS, DOrthRCSEng ${ }^{c}$ \\ Burnley and Manchester, United Kingdom
}

The aim of this study was to evaluate the effectiveness of incremental and maximum bite advancement during treatment of Class II Division 1 malocclusion with the Twin-block appliance in the permanent dentition. It was performed at 3 district general hospitals in the United Kingdom with 4 operators. Two hundred three patients, 10-14 years old, were randomized. Control patients had the initial bite taken edge-to-edge for appliance construction with a standard Twin-block. Experimental patients had $2 \mathrm{~mm}$ initial bite advancement and subsequent $2 \mathrm{~mm}$ advancements at 6 weekly intervals with a Twin-block appliance incorporating advancement screws. Data were collected at the start and the finish of Twin-block treatment. The use of incremental advancement of the Twin-block did not confer any advantages in terms of process and outcome of the treatment. However, patient compliance was influenced by operator and patient age. The duration of treatment was influenced by operator and initial overjet. Incremental bite advancement produced no advantages over maximum advancement. (Am J Orthod Dentofacial Orthop 2004;126:583-8)

$\mathbf{T}$ The amount of bite advancement incorporated into functional appliances during construction remains controversial. ${ }^{1}$ Several recommendations have been made by various authors: Andresen originally recommended advancing the bite to a Class I molar relationship, whereas others favored edge-toedge incisors, suggesting that this would maximize the orthopedic effect. ${ }^{2-7}$ Other clinicians activate the bite in small stages, ${ }^{8-11}$ stating that this improves patient speech and comfort with greater chance of maintaining correct appliance position during sleep. In addition, compliance might be greater with small increments of mandibular advancement because of reduced tension in the craniofacial musculature.

Few studies have investigated the clinical effects of different amounts of protrusive bite activation in functional appliances. Those published have small sample

\footnotetext{
${ }^{a}$ Consultant orthodontist, Burnley General Hospital, Burnley, United Kingdom. ${ }^{\mathrm{b}}$ Research associate, University Dental Hospital of Manchester, Manchester, United Kingdom.

'Professor and chair, Unit of Orthodontics, University Dental Hospital of Manchester, Manchester, United Kingdom.

The study was supported by the British Orthodontic Society 1998 Research and Audit Award.

Reprint requests to: Mr P. A. Banks, Orthodontic Department, Burnley General Hospital, Casterton Ave, Burnley, Lancashire, BB10 2PQ, United Kingdom; e-mail, philbanks_burnly@yahoo.com.

Submitted, February 2004; revised and accepted, March 2004. 0889-5406/\$30.00

Copyright (C) 2004 by the American Association of Orthodontists. doi:10.1016/j.ajodo.2004.03.024
}

sizes without a power calculation, did not randomize treatments, and did not report clinical success rates. ${ }^{10,12,13}$ As a result, no clear evidence exists. In this study, we aimed to maximize robustness of the method by enrolling enough subjects, by randomizing treatments, and by evaluating clinical success rates. We used the Twin-block because a recent survey showed that it is the most popular functional appliance in the United Kingdom. ${ }^{14}$

This study had the following null hypotheses: There is no difference between incremental advancement and maximum bite advancement during Twin-block treatment with respect to treatment completion rate, duration of treatment, overjet at the end of treatment, and final skeletal discrepancy.

\section{MATERIAL AND METHODS}

Treatment was provided by 4 experienced clinicians working in 3 orthodontic clinics.

Patient selection criteria were as follows: overjet of $7 \mathrm{~mm}$ or more; no previous appliance therapy; permanent dentition stage, age 10-14 years; and no significant medical history.

A $20 \%$ difference between the groups in compliance rate was thought to be clinically significant. On this basis, with alpha at 0.05 and the study power at 0.85 , we needed 80 patients per group. To allow for 

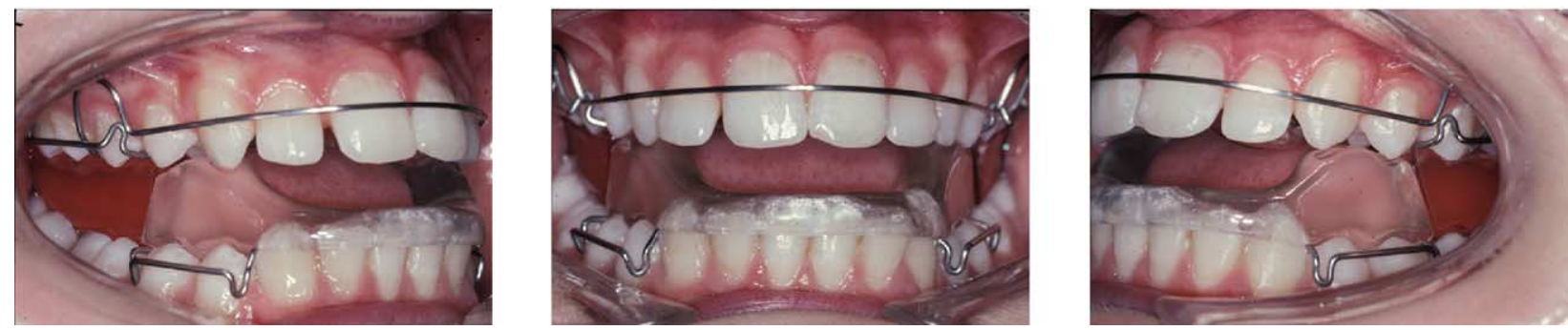

Fig 1. Standard Twin-block appliance.
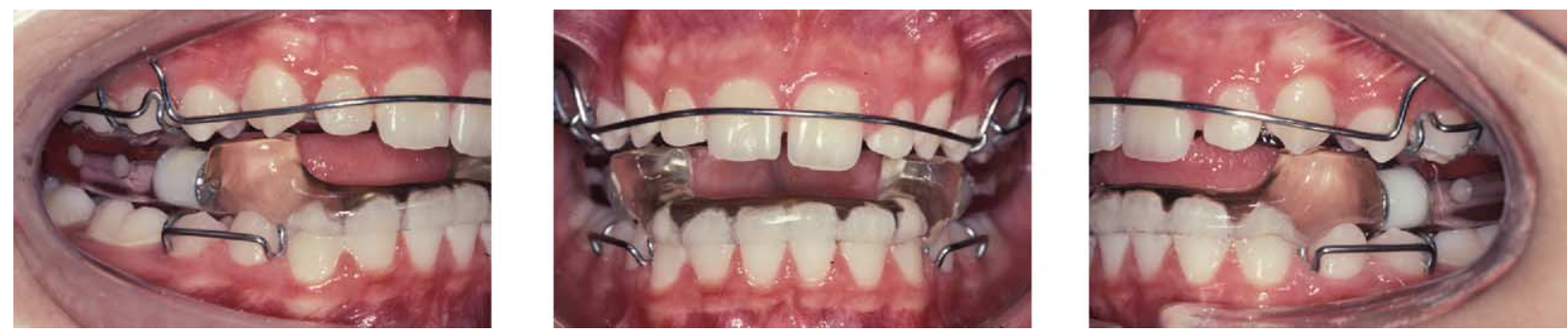

Fig 2. Incremental advancement Twin-block appliance.

$20 \%$ treatment discontinuation, we recruited over 200 patients with an intention to treat analysis.

The patients were randomized to either the control or the experimental group and were stratified by sex and operator in blocks of 10 . The study was coordinated from 1 site. We performed manual allocation using sealed envelopes to blind the operator during enrollment of patients in the study. This enabled approximately equal distribution of patients from each group in each clinic and between operators. Patient consent was obtained, and ethical approval for the study was obtained from the local research ethics committees.

The Twin-block design was identical for both groups of patients (Figs 1 and 2). Retention was by double Adams clasps in 0.8-mm stainless steel on the maxillary first molars and second premolars and the mandibular first and second premolars. A maxillary labial bow in $0.8 \mathrm{~mm}$ stainless steel was used passively unless the incisors were proclined. When maxillary arch expansion was required, a midline screw was used and turned once per week, and individual Z-springs were placed as required to align the maxillary incisors. Mandibular incisal capping was used (to prevent appliance midline fractures), and all appliances were constructed with a high-quality self-curing acrylic. The blocks were approximately $6 \mathrm{~mm}$ in height with $70^{\circ}$ inclines. The only design difference was the incorporation of advancement screws and housings into the maxillary appliance blocks in the experimental group (Ortho-Care [UK], Bradford, United Kingdom).

We used a graduated fork for bite registration (George Gauge, American Orthodontics UK, High Wycombe, United Kingdom) with 4-mm fork thickness and wax blocks. Control patients had the initial protrusive bite taken for appliance construction in the edgeto-edge position. If this was not possible, bite registration was carried out in the most protrusive position that was comfortable for the patient. Any necessary subsequent bite reactivation was carried out by adding self-curing acrylic in the laboratory after taking a new bite registration.

The experimental patients had an initial bite advancement of $2 \mathrm{~mm}$ with the bite fork. The appliances incorporated the Twin-block advancement system screws in the maxillary blocks. ${ }^{15,16}$ Further chair-side bite advancements were produced by the bilateral addition of 2-mm thick acetal spacers to the maxillary block advancement screws at 6 weekly intervals.

Treatment was discontinued after 3 failed appointments, $10 \%$ or less overjet reduction over 6 months, or excessive appliance breakages or loss at the operator's discretion.

Data were collected at the start of active treat- 
Table I. Outcome and process data for trial (means with 95\% confidence intervals in parentheses)

\begin{tabular}{lcc}
\hline \multicolumn{1}{c}{ Factor } & $\begin{array}{c}\text { Maximum advancement } \\
\text { Twin-block group } \\
\text { (control) }\end{array}$ & $\begin{array}{c}\text { Incremental advancement } \\
\text { Twin-block group } \\
\text { (experimental) }\end{array}$ \\
\hline Age (years) & $12.60(12.30$ to 12.87$)$ & $12.62(12.41$ to 12.83$)$ \\
Duration of treatment (months) & $7.02(6.34$ to 7.70$)$ & $7.40(6.71$ to 8.09$)$ \\
Discontinuation of treatment $(\%)$ & $29.8 \%$ & $18.9 \%$ \\
Carstairs social deprivation score & $1.26(0.36$ to 2.15$)$ & $1.47(0.58$ to 2.36$)$ \\
\hline
\end{tabular}

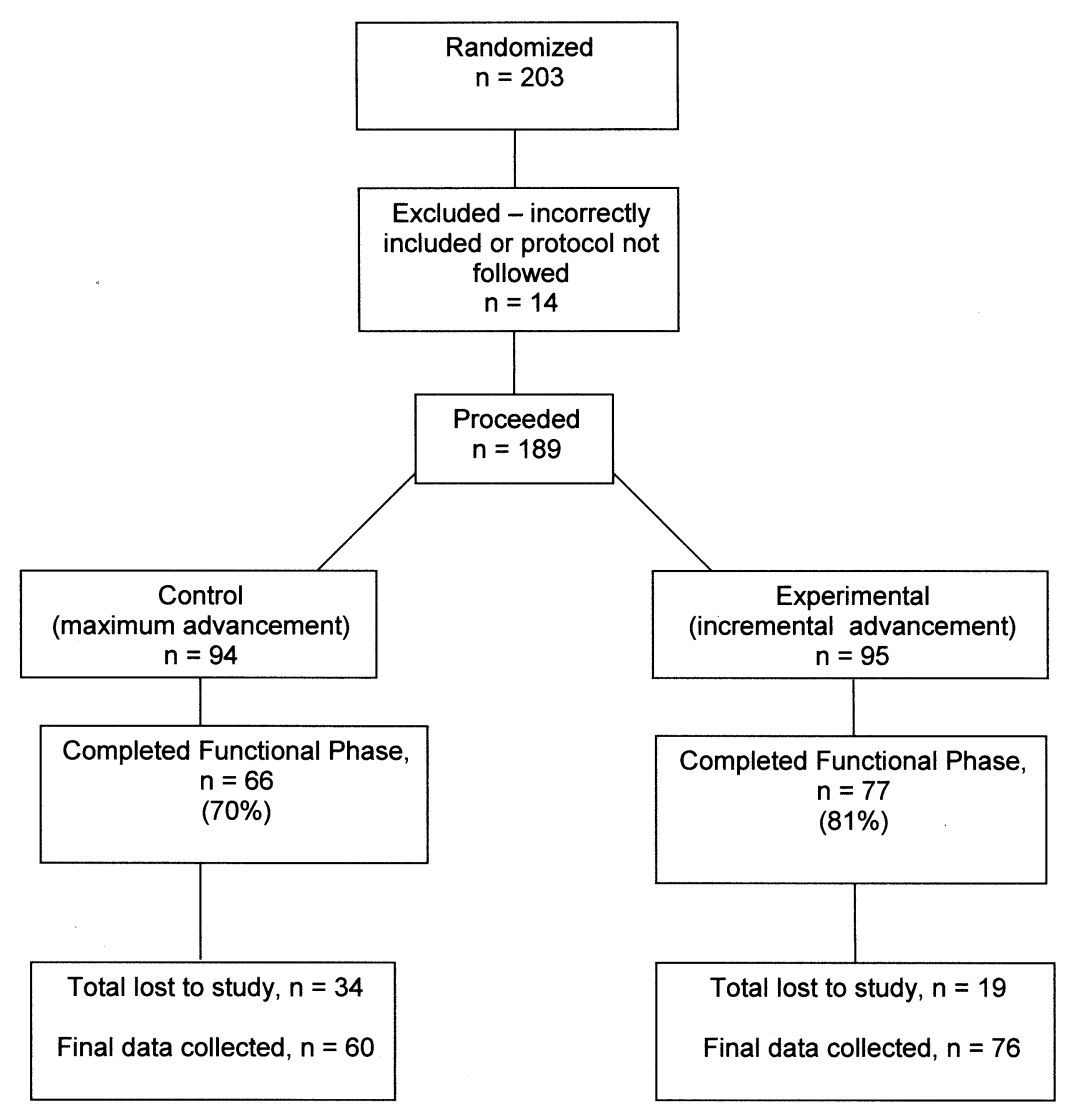

Fig 3. Flow chart of patients in trial.

ment, and at the end of active Twin-block treatment (at overjet reduction). These comprised (1) cephalometric radiographs, (2) number and magnitude of bite advancements during treatment, (3) patient's date of birth, (4) patient's postal code (used to obtain data on level of social deprivation, according to the Carstairs index ${ }^{17}$ a composite index of deprivation derived from United Kingdom national census data), (5) reasons for treatment discontinuation, and (6) patient's clinical record.

Cephalograms were corrected for magnification and analyzed by using the Pancherz method. ${ }^{6}$ When mea- suring the cephalograms, the examiner was unaware of the group to which the patient had been allocated. Thirty films were retraced, and the error was assessed. The intraclass correlation coefficient for cephalometric landmark identification and digitizing ranged from 0.96 for $\mathrm{Pg} / \mathrm{OLp}$ to 0.98 for Is/Olp, and ii/Olp. The root mean square (SD of the error) ranged from $0.61 \mathrm{~mm}$ for position of the maxillary base to 0.92 for Pg/OLp. These were acceptable error levels.

Cervical spine maturation was assessed by the method of Hassel and Farman. ${ }^{18}$ Thirty sets of radiographs were reanalyzed, and the error was evaluated 
Table II. Pancherz analysis variables at start and at end of Twin-block treatment

\begin{tabular}{|c|c|c|c|c|c|c|c|c|}
\hline & \multicolumn{4}{|c|}{ Control $(n=60)$} & \multicolumn{4}{|c|}{ Experimental $(n=76)$} \\
\hline & \multicolumn{2}{|r|}{ Before } & \multicolumn{2}{|r|}{ After } & \multicolumn{2}{|r|}{ Before } & \multicolumn{2}{|r|}{ After } \\
\hline & Mean & $95 \% C I$ & Mean & $95 \% C I$ & Mean & $95 \% C I$ & Mean & $95 \% C I$ \\
\hline \multicolumn{9}{|l|}{ Overjet } \\
\hline $\begin{array}{l}\text { Is/OLp minus } \\
\text { ii/Olp }\end{array}$ & +9.07 & +8.55 to +9.58 & +1.77 & +1.39 to +2.16 & +9.13 & +8.70 to +9.57 & +1.23 & +0.77 to +1.69 \\
\hline \multicolumn{9}{|l|}{ Molar relation } \\
\hline $\begin{array}{l}\mathrm{Ms} / \text { Olp minus } \\
\text { mi/Ollp }\end{array}$ & +1.49 & +0.90 to +2.09 & -4.54 & -5.14 to -3.93 & +1.12 & +0.63 to +1.60 & -2.78 & -5.25 to -0.31 \\
\hline \multicolumn{9}{|l|}{ Maxillary base } \\
\hline $\begin{array}{l}\text { A point to Olp } \\
\text { Mandibular base }\end{array}$ & +70.41 & +69.22 to +71.60 & +72.22 & +70.87 to 73.56 & +70.79 & +69.90 to +71.67 & +72.50 & +71.48 to +73.52 \\
\hline $\begin{array}{l}\mathrm{Pg} / \mathrm{Olp} \\
\text { Skeletal discrepancy }\end{array}$ & +69.80 & +68.38 to +71.22 & +73.98 & +72.51 to +75.45 & +69.91 & +67.55 to +72.26 & +73.89 & +71.25 to +76.53 \\
\hline $\begin{array}{l}\text { A point to Olp - } \\
\text { Pg/Olp }\end{array}$ & +0.61 & -0.19 to +1.40 & -1.77 & -2.74 to -0.80 & +0.88 & -1.37 to +3.14 & -1.39 & -3.76 to +0.98 \\
\hline $\begin{array}{l}\text { Maxillary incisor } \\
\text { is/Olp - ss/Olp } \\
\text { Mandibular incisor }\end{array}$ & +8.39 & +7.88 to +8.90 & +5.58 & +4.92 to +6.25 & +8.61 & +8.15 to +9.07 & +5.11 & +4.54 to +5.68 \\
\hline $\begin{array}{l}\text { ii/OLP - Pg/Olp } \\
\text { Maxillary molar }\end{array}$ & -0.071 & -0.90 to +0.76 & +2.04 & +1.14 to +2.95 & +0.36 & -1.80 to +2.52 & +2.49 & +0.10 to +4.87 \\
\hline $\begin{array}{l}\mathrm{ms} / \mathrm{Olp} \text { - ss/Olp } \\
\text { Mandibular molar }\end{array}$ & -22.10 & -22.86 to -21.34 & -24.13 & -24.81 to -23.46 & -22.14 & -22.53 to -21.75 & -24.08 & -24.57 to -23.59 \\
\hline $\mathrm{mi} / \mathrm{Olp}-\mathrm{Pg} / \mathrm{Olp}$ & -22.99 & -23.86 to -22.11 & -21.37 & -22.20 to -20.53 & -22.37 & -24.58 to -20.16 & -22.69 & -26.08 to -19.31 \\
\hline
\end{tabular}

with the kappa statistic, giving a kappa value of 0.94 ; this was acceptable.

\section{Data analysis}

We decided to restrict data analysis to a few variables to reduce the chance of false positives and other spurious findings resulting from multiple comparisons across related variables. As a result, the data analysis was restricted to generation of descriptives and regression analyses on whether the patient completed Twin-block treatment, duration of treatment, the final anteroposterior skeletal discrepancy as calculated by the Pancherz analysis (defined as A/OLp minus Pg/ OLp), and the final overjet.

We carried out an intention-to-treat analysis so that the data from all patients, regardless of treatment outcome, were included in the analysis. This comprised an analysis of all patients who entered the trial and for whom baseline and final records were available.

The stages of this analysis were generation of descriptives, initial comparison of groups, and regression analysis on whether the patients satisfactorily completed the Twin-block treatment.

The following variables were included at the start of the modeling process: (1) baseline data on the dependent variable, (2) treatment group, (3) age, (4) sex, (5) center and center/treatment group interaction term, (6) cervical spine maturation staging, (7) Carstairs deprivation score, and (8) time from registration to second cephalogram.
The regressions were carried out by using sums of squares type II.

When variables were removed, the regression coefficients and adjusted $\mathrm{R}^{2}$ were compared with the previous model to check stability of effect. All models were tested for homogeneity of variance and normality of residuals.

\section{RESULTS}

Two hundred three patients were enrolled in the study (Table I), but 14 were either incorrectly included or suffered a protocol deviation. Of the remaining 189 patients, 94 (47 boys, 47 girls) were allocated to the maximal advancement group, and 95 (47 boys, 48 girls) were allocated to the incremental advancement group. A flow chart of the patients is given in Figure 3.

The numbers of patients who successfully completed the Twin-block treatment phase were $66(70 \%)$ for the maximum advancement group and $77(81 \%)$ for the incremental advancement group. Some who discontinued treatment were lost to the study; final data were collected for 60 and 76 patients, respectively.

The data for the cephalometric analysis at the start and end of the study are shown in Table II; Table III contains data on the change in cephalometric variables.

We could not fit satisfactory models for the final overjet and skeletal discrepancy, and no difference was detected with the $t$ test. However, models were fitted for completion and duration of treatment. These are shown in Tables IV and V, respectively. 
Table III. Change in Pancherz analysis variables at end of Twin-block treatment

\begin{tabular}{|c|c|c|c|c|}
\hline & \multicolumn{2}{|c|}{ Control $(n=60)$} & \multicolumn{2}{|c|}{ Experimental $(n=76)$} \\
\hline & Mean & $95 \% C I$ & Mean & $95 \% C I$ \\
\hline \multicolumn{5}{|l|}{ Overjet } \\
\hline $\begin{array}{l}\text { Is/OLp minus ii/OLp } \\
\text { Molar relation }\end{array}$ & -7.29 & -7.89 to -6.70 & -7.90 & -8.54 to -7.27 \\
\hline $\begin{array}{l}\text { Ms/OLp minus mi/Ollp } \\
\text { Skeletal changes }\end{array}$ & -6.03 & -6.66 to -5.40 & -3.89 & -6.33 to -1.45 \\
\hline Maxillary base & & & & \\
\hline $\begin{array}{l}\text { A point to Olp } \\
\text { Mandibular base }\end{array}$ & +1.81 & +1.02 to +2.60 & +1.71 & +1.05 to +2.37 \\
\hline $\begin{array}{l}\mathrm{Pg} / \mathrm{Olp} \\
\text { Skeletal change }\end{array}$ & +4.18 & +3.21 to +5.16 & +3.98 & +0.73 to +7.24 \\
\hline A point to $\mathrm{Olp}-\mathrm{Pg} / \mathrm{Olp}$ & -2.37 & -3.21 to -1.54 & -2.27 & -5.46 to +0.91 \\
\hline \multicolumn{4}{|l|}{ Dental changes } & \\
\hline Is/Olp -ssOLp & -2.81 & -3.34 to -2.27 & -3.50 & -4.00 to -3.00 \\
\hline $\begin{array}{l}\text { ii/OLP Pg/OLp } \\
\text { Maxillary molar }\end{array}$ & +2.11 & +1.53 to +2.70 & +2.13 & -0.98 to +5.23 \\
\hline $\begin{array}{l}\mathrm{ms} / \mathrm{Olp} \text { - ss/OIP } \\
\text { Mandibular molar }\end{array}$ & -2.04 & -2.62 to -1.45 & -1.95 & -2.39 to +1.50 \\
\hline $\mathrm{mi} / \mathrm{Olp}-\mathrm{Pg} / \mathrm{OLp}$ & +1.62 & +1.05 to +2.19 & -0.33 & -4.25 to +3.60 \\
\hline
\end{tabular}

Table IV. Regression analysis on dependent variable of patients who completed Twin-block appliance phase of treatment

\begin{tabular}{lcccc}
\hline \multicolumn{1}{c}{ Significant variables } & $\begin{array}{c}\text { Regression } \\
\text { coefficient }\end{array}$ & $\begin{array}{c}\text { Odds ratio for non } \\
\text { completion of functional } \\
\text { treatment }\end{array}$ & $\begin{array}{c}\text { 95\% confidence } \\
\text { interval of odds ratio }\end{array}$ & Significance \\
\hline Age & -1.12 & 0.33 & 0.13 to 0.80 & 0.014 \\
$\begin{array}{l}\text { Older patients }(>=12.3 \text { years compared } \\
\quad \text { with lowest third (<12.3 years) }\end{array}$ & -2.69 & 0.068 & 0.007 to 0.68 & 0.022 \\
$\begin{array}{l}\text { Operator 1 } \\
\text { Operator 2 compared with main operator }\end{array} \quad 2.05$ & 7.78 & 1.01 to 60.01 & 0.049 \\
$\quad$ and operator 3 & 1.844 & 6.58 & $P<.0005$ \\
Constant & & & $P$ \\
\hline
\end{tabular}

It appears that the only variables that influence whether a patient completed treatment were age and operator. This showed that patients aged 12.3 years or less were 3 times more likely to complete treatment than older patients. Although there was an operator effect, the $95 \%$ confidence intervals were large, and the values of the odds ratios should be viewed in this light.

Similarly, the only variables that influenced the duration of treatment were the operator and the initial overjet.

Whether the Twin-block had been advanced with a maximum or an incremental advancement did not influence any outcome variable.

\section{DISCUSSION}

The most important finding of this study was that the use of incremental advancement of the Twin-block did not influence the outcome of treatment, in terms of process or morphological effects. As a result, we cannot support the suggestion that maximum bite advancement produces a better orthopedic response. It was surprising that the significantly greater forces that must have been applied to the dentition in the control group did not result in more mandibular incisor proclination. This is probably not related to the mandibular incisal capping because the amount of proclination is similar to that in other studies when no capping was used. It appears in this study that the degree of incisor tipping was independent of the forces applied, although the force levels were not quantified. It is of interest that 6 weekly bite advancements of $2 \mathrm{~mm}$ gave a satisfactory result and produced skeletal and dental changes equal to those of maximum activation. This suggests that the degree 
Table V. Regression on duration of treatment in months

\begin{tabular}{cccc}
\hline $\begin{array}{c}\text { Significant } \\
\text { variables }\end{array}$ & Coefficient & $\begin{array}{c}95 \% \text { confidence } \\
\text { interval for } \\
\text { coefficient }\end{array}$ & Significance \\
\hline Pretreatment overjet & -0.29 & -0.52 to -0.06 & $P=.14$ \\
Operator 1 & -3.53 & -7.49 to +0.44 & $P=.014$ \\
2 & 0.078 & -1.83 to +1.99 & \\
3 & -1.57 & -3.15 to -0.002 & \\
4 & 0 & & \\
\hline
\end{tabular}

Model $\mathrm{n}=136$.

Model significance, $\mathrm{P}<.001$.

Adjusted $\mathrm{R}^{2}, 0.11$.

of force generated by stretching the orofacial muscles and other soft tissues is not critical in inducing this type of tooth movement.

When we evaluated the patient and operator variables, we found that compliance was significantly better in patients who were younger at the start of treatment. This agrees with another randomized Twinblock study carried out in the mixed dentition ${ }^{19}$ and certainly requires further investigation, because the reasons that the younger patients were more compliant are unknown. Another surprising finding was the variability of clinical success between clinicians. This cannot be explained readily but indicates that the appliance is operator-sensitive and is a factor to be considered when planning treatment.

Other factors that had no influence on the results of this study are equally important. For example, the stage of maturity of the cervical spine did not influence the outcome of treatment. This agrees with the results of another prospective randomized trial into Twin-block treatment and certainly adds to the prospective evidence that casts doubt on the use of maturation indicators based on the cervical spine. ${ }^{20}$ Either this method of measuring maturation has limited validity or the outcome of treatment is not related to skeletal maturation. This is a controversial area, and this conclusion might be explained by considering that other investigations that support this hypothesis are retrospective and, therefore, suffer from biases that are minimized when prospective research designs are used.

\section{CONCLUSIONS}

There appears to be no advantage of using incremental bite advancement in Twin-block therapy. Duration and success of treatment are influenced by operator and age of the patient. Cervical spine growth stage does not influence the outcome of Twin-block functional appliance treatment.
We thank Mrs C. McDade, Mr S. M. Chadwick, and Dr C. R. Mattick for treating some of the patients, and Messrs G. J. Carmichael, R. Scholes, and Miss C. Smith for appliance construction.

\section{REFERENCES}

1. Bishara ES, Ziaja RR. Functional appliances: a review. Am J Orthod Dentofacial Orthop 1989;95:250-8.

2. Björk A. The principle of the Andresen method of orthodontic treatment: a discussion based on cephalometric $\mathrm{x}$-ray analysis of treated cases. Am J Orthod 1951;37:437-58.

3. Wieslander L, Lagerstrom L. The effect of activator treatment on Class II malocclusions. Am J Orthod 1979;75:20-6.

4. Herren P. The activator's mode of action. Am J Orthod 1959; 45:512-27.

5. Korkhaus G. Present orthodontic thought in Germany. Am J Orthod 1960;46:270-87.

6. Pancherz H. The mechanism of Class II correction in Herbst appliance treatment: a cephalometric investigation. Am J Orthod 1982;82:104-13.

7. Clark WJ. Twin-block functional therapy. Turin: Mosby-Wolfe; 1995.

8. Bass NM. Orthopedic coordination of dentofacial development in skeletal Class II malocclusion in conjunction with edgewise therapy. Part 1. Am J Orthod 1983;84:361-83.

9. Malmgren O, Ömblus J. Treatment with an orthopaedic appliance system. Eur J Orthod 1985;7:205-14.

10. Falck F. Fränkel R. Clinical relevance of step-by-step mandibular advancement in treatment of mandibular retrusion using the Fränkel appliance. Am J Orthod Dentofacial Orthop 1989;96:333-43.

11. Orton HS. Functional appliances in orthodontic treatment. London: Quintessence; 1990.

12. DeVincenzo JP, Winn MW. Orthopedic and orthodontic effects resulting from the use of a functional appliance with different amounts of protrusive activation. Am J Orthod Dentofacial Orthop 1989;96:181-90.

13. Du X, Hägg U, Rabie A. Effects of headgear Herbst and mandibular step-by-step advancement versus conventional Herbst appliance and maximal jumping of the mandible. Eur J Orthod 2002;24;167-74.

14. Chadwick SM, Banks PA, Wright JL. The use of myofunctional appliances in the UK: a survey of british orthodontists. Dent Update 1998;25:302-8.

15. Carmichael GJ, Banks PA, Chadwick SM. A modification to enable controlled progressive advancement of the Twin-block appliance. Br J Orthod 1999;26:9-13.

16. Banks PA, Carmichael GJ. Stepwise overjet reduction by a modified Twin-block appliance. J Clin Orthod 1999;33:620-3.

17. Carstairs V. Multiple deprivation and health state. Community Med 1981;3:4-13.

18. Hassel B, Farman AG. Skeletal maturation evaluation using cervical vertebrae. Am J Orthod Dentofacial Orthop 1995;107:58-66.

19. O' Brien K, Wright JL, Conboy F, Sanjie Y, Mandall N, Chadwick S, et al. Effectiveness of early orthodontic treatment with the Twin-block appliance: a multicenter, randomized, controlled trial. Part 1: dental and skeletal effects. Am J Orthod Dentofacial Orthop 2003;124:234-43.

20. O' Brien K, Wright JL, Conboy F, Sanjie Y, Mandall N, Chadwick S, et al. Effectiveness of treatment for Class II malocclusion with the Herbst or Twin-block appliances: a randomized, controlled trial. Am J Orthod Dentofacial Orthop 2003;124:128-37. 